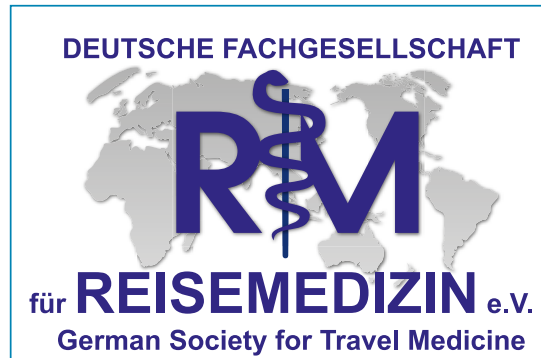

Hansaallee 299, 40549 Düsseldorf

Tel.: 0211/5202581 Fax: 0211/5202583

E-Mail: info@fachgesellschaft-reisemedizin.de www.fachgesellschaft-reisemedizin.de

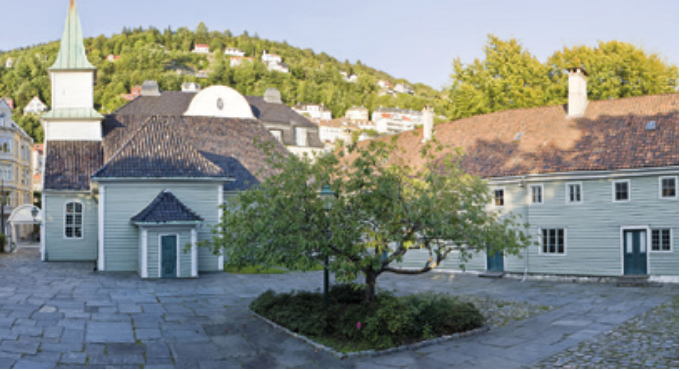

Abb. 1 Das ehemalige Leprakrankenhaus St. George in Bergen.

Quelle: @Bergen City Museum / Regin Hjertholm

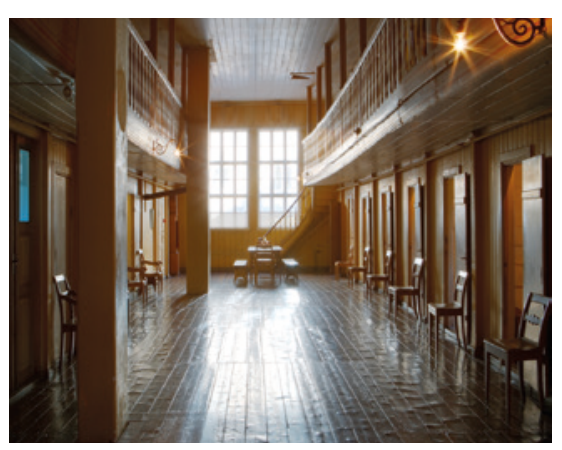

Abb. 2 Heute Museum: das ehemalige Wohn- und Behandlungsgebäude des St. George.

Quelle: @Bergen City Museum/Regin Hjertholm

\title{
Sehr verehrte Frau Kollegin, sehr geehrter Herr Kollege,
}

nach jetzigem Stand haben die Fußballfans außer der Freude über den gewonnenen Pokal und die eine oder andere schöne Erinnerung nichts mitgebracht, zumindest nicht die im Vorfeld für möglich bis wahrscheinlich gehaltenen Dengue- oder Influenzainfektionen. Dies geht aus den aktuellen Auswertungen der Landesmeldestellen für das Infektionsschutzgesetz (IfSG) hervor: ,Kein Hinweis auf Krankheitshäufungen bei Reiserückkehrern aus Brasilien'. Auch die zwischen dem 5. Juni und 20. Juli 2014 von der ECDC durchgeführte europaweite erweiterte Surveillance gibt bislang keinen Hinweis auf unerwartete Krankheitshäufungen.

Bedenklich stimmen dagegen die deutlich erhöhten Erkrankungszahlen an Chikungunya in der Karibik und den USA, darunter erste autochthone Fälle aus Florida, einem klassischen Reiseziel für Westeuropäer (www.cdc.gov/chikungunya/). Dies korrespondiert mit einer gegenüber dem Meldezeitraum des Vorjahres 7-fach erhöhten Meldeziffer in Baden-Württemberg (jeweils bis 30. Meldewoche): ein Fall 2012, 2 Fälle 2013, 14 Fälle 2014, davon 6 aus der Dominikanischen Republik.

Die Entwicklung des Erkrankungsgeschehens durch das Coronavirus MERS (Middle East Respiratory Syndrome) verdient unsere volle Aufmerksamkeit. Einem Bericht der Ärzte-Zeitung online vom 23.07.2014 zufolge könne „MERS fliegen“. Einer Forschungsgruppe aus Saudi-Arabien sei es gelungen, in der Raumluft einer Kamelscheune Genfragmente des Virus nachzuweisen. Die Fragmente stimmten mit Proben überein, die sie bei einigen Tieren sowie von dem erkrankten Besitzer der Tiere entnommen hatten (Azhar EI et al. MBio 2014; 5, pii: e01450-14, Open Access: http://mbio. asm.org/content/5/4/e01450-14.

Das dortige Ministerium für den Hadsch hat deshalb verfügt, in diesem Jahr zum großen Opferfest keine Kamele zu schlachten. Die Tradition der Kamelschlachtung geht auf die in Hadithe überlieferten Worte des Propheten zurück. Die DFR war Mitveranstalterin der 5. Nordeuropäischen Konferenz für Reisemedizin (NECTM) vom 5. bis 8. Juni 2014 in Bergen, Norwegen.
Als kleine Reminiszenz an Bergen ist hier ein Blick auf Dr. Armauer Hansen und das Leprakrankenhaus St. George: Zwischen 1850 und 1900 gab es in Bergen 3 Leprakrankenhäuser, von denen nur das

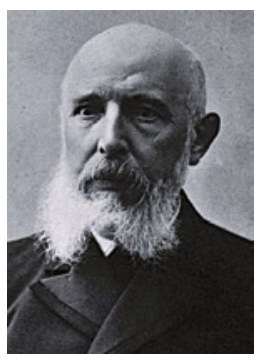

G. H. Armauer Hansen (1841-1912)
St. George bis in das 20. Jahrhundert betrieben wurde. Der letzte Patient starb Ende der dreißiger Jahre. Die Bilder zeigen den Innenhof des Gebäudegevierts (Abb. 1): rechts hinten das Wohngebäude des Personals. Abbildung 2 zeigt den aktuellen Blick in das Wohn- und Behandlungsgebäude: Die Leprakranken waren sehr bescheiden in kleinen Räumen links und rechts sowie im ersten Stock untergebracht. Heute ist dieses Gebäude Museum und unbedingt besuchenswert. Dr. Armauer Hansen (29.07.1841-12.02.1912), Arzt und Zoologe, beschrieb am 28. Februar 1873, nachdem er sich in Bonn und Wien die neuesten histologischen Techniken angeeignet hatte, das Mycobacterium leprae, möglicherweise zugleich der erste Nachweis eines Bakteriums als infektiöse und übertragbare Ursache einer Krankheit. Lassen Sie mich mit einer herzlichen Einladung zu unserer diesjährigen Jahrestagung und $\mathrm{zu}$ unserer Mitgliederversammlung schließen. Die Tagesordnung dürfte Ihnen in den letzten Tagen in unserem Mitgliederrundschreiben zugegangen sein.

Mit den besten Grüßen

Ihr

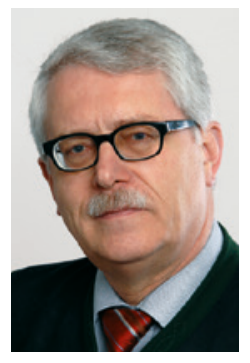

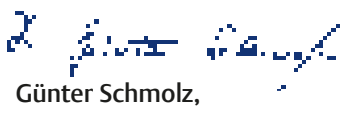
Stuttgart 


\title{
17. Jahrestagung der Deutschen Fachgesellschaft für Reisemedizin e. V.
}

\author{
26.-27.09.2014 in Nürnberg \\ Veranstaltungsort: Le Méridien Grand Hotel Nürnberg • Bahnhofstr. 1-3 • 90402 Nürnberg \\ Freitag, 26.09.2014 \\ 12:30 Uhr Begrüßungsimbiss \\ 13:00-13:15 Uhr Begrüßung und Eröffnung der 17. Jahrestagung \\ Prof. Dr. Günter Schmolz, Stuttgart \\ 09:00-09:45 Uhr Hauterkrankungen als Reisemitbringsel \\ Dr. Viktor A. Czaika, Berlin \\ $\begin{array}{ll}\text { 13:15-14:00 Uhr } \quad \begin{array}{l}\text { Analyse der Immunantwort nach } \\ \text { Gelbfieberimpfung }\end{array} & \end{array}$ \\ Prof. Dr. Matthias Niedrig, Berlin \\ 14:00-14:45 Uhr Aktuelles zu den Mindestanforderungen und \\ Standards bei der Entsendung von Freiwilligen \\ (am Beispiel des weltwärts Programmes) \\ Dr. K. Peter Schmitz, Bonn \\ 09:45-10:30 Uhr Praktische Umsetzung der Vorsorge G 35 nach \\ den Vorgaben der ArbMedVV (Neufassung) \\ Dr. Uwe Ricken, Bad Essen \\ 10:30-11:00 Uhr Kaffeepause \\ 11:00-11:45 Uhr Mass gatherings \\ Prof. DDr. Martin Haditsch, Hannover \\ 11:45-12:30 Uhr $\quad$ Fume Events - ein Update \\ Prof. Dr. Dirk-Matthias Rose, Frankfurt \\ 14:45-15:15 Uhr Kaffeepause \\ 15:15-16:00 Uhr $\quad$ Aktuelle Weltseuchenlage, neue Impfstoffe \\ Prof. Dr. Tomas Jelinek, Berlin \\ 12:30-13:30 Uh \\ Mittagspause \\ 13:30-14:15 Uhr Infektionsrisiken an Bord von Flugzeugen \\ Dr. Burkhard Rieke, Düsseldorf \\ 16:00-16:45 Uhr Gesundheitsrisiken beruflich Reisender \\ Dr. Stefan Eßer, Neu-Isenburg \\ 14:15-15:00 Uhr \\ Knifflige Impffragen \\ Mitgliederversammlung \\ 16:45 Uhr \\ Stadtrundgang ab Tagungshotel, \\ anschließend gemeinsames Abendessen \\ Dr. Sigrid Ley-Köllstadt, Marburg \\ 18:30 Uhr \\ im Restaurant Heilig Geist Spital \\ 15:00-15:30 Uhr \\ 15:30-16:15 Uhr \\ 16:15-17:00 Uhr \\ 17:00 Uhr \\ Kaffeepause \\ Reisen mit neurologischen Erkrankungen \\ Dr. Martin Rösener, Stuttgart \\ Reisen mit psychischen Erkrankungen \\ Prof. Dr. Dipl-Psych. Gerd Laux, Haag i. OB \\ Verabschiedung \\ Dr. Uwe Ricken, Bad Essen \\ Informationen und Anmeldung \\ Deutsche Fachgesellschaft für Reisemedizin e.V. \\ Hansaallee 299 40549 Düsseldorf \\ Tel.: 02115202581 · Fax: 02115202583 \\ www.fachgesellschaft-reisemedizin.de \\ Die Veranstaltung wurde von der Bayerischen Landesärztekammer \\ mit 12 Fortbildungspunkten zertifiziert.
}

